\title{
Advisory, Collaborative and Scrutinizing Roles of Deliberative Mini-Publics
}

\author{
Maija Setälä * \\ Department of Philosophy, Contemporary History and Political Science, University of Turku, Turku, Finland
}

The normative point of departure in this article is that mini-publics can "complement" representative democracy only if they enhance inclusive processes of mutual justification among elected representatives who are responsible for public decisions. This article distinguishes three different roles of mini-publics in representative decision-making. Minipublics can be 1) advisory when they provide input for collective will-formation in the representative arena, 2) collaborative when they involve elected representatives in the deliberative process, 3) scrutinizing when they check representative decision-making. The article analyzes strengths and weaknesses of these roles of mini-publics. Advisory minipublics are particularly vulnerable to "cherry-picking." While collaborative uses of minipublics may facilitate inclusive reason-giving among elected representatives, they entail risks of representative dominance. Scrutinizing use of mini-publics seem particularly promising from the normative perspective, but it requires a well-defined institutional

Edited by:

Pierre-Etienne Vandamme, Université libre de Bruxelles, Belgium

Reviewed by: Sergiu Gherghina, University of Glasgow, South United Kingdom Andrea Felicetti, Normal School of Pisa, Italy

*Correspondence: Maija Setälä maiset@utu.fi

Specialty section: This article was submitted to Elections and Representation, a section of the journal Frontiers in Political Science

Received: 05 August 2020 Accepted: 16 December 2020 Published: 25 January 2021

Citation:

Setälä M (2021) Advisory, Collaborative and Scrutinizing Roles of

Deliberative Mini-Publics.

Front. Polit. Sci. 2:591844. doi: 10.3389/fpos.2020.591844 framework. The article concludes that while there are ways to avoid problems emerging in these different roles, political context is crucial in terms of the deliberative impact of mini-publics.

Keywords: deliberative mini-public, random selection, representative democracy, inclusion, deliberative democracy

\section{INTRODUCTION}

Deliberative mini-publics are specific forums designed to enhance inclusive deliberation among randomly selected citizens (Setälä and Smith 2018). During the past few decades, mini-publics have been increasingly organized at different levels of governance around the world. The topics of minipublics have covered a wide range of policy areas, including moral and ethical issues such as abortion and same-sex marriage, scientifically and technically complex issues related, for example, to bioethics and information technology, as highly politicized issues such as European integration and climate transitions.

One of the key design features of mini-publics is that the group of participants should be broadly speaking representative in terms of socio-demographics and/or viewpoints on the issue at hand (Brown 2006). Fishkin (2009) argues that mini-publics should, by definition, be based on random selection of participants. Random selection is a highly egalitarian method giving each citizen an equal probability to be selected to serve the public. While the use of random sampling has become one of the defining characteristics of deliberative mini-publics, there are different views of whether it should be the only method of recruiting participants. There are strong arguments in favor of the view that random sampling should be combined with stratification or quota methods in order to ensure representation of diversity of societal viewpoints, including marginalized groups, and to counteract self-selection biases (see e.g., Farrell et al., 2019). 
In order to facilitate a good-quality deliberative process, interaction with expert information as well as moderated discussions in small groups are other key design features of mini-publics. While all mini-publics share these key features, there are also significant differences between various mini-public designs such as Consensus Conferences, Citizens' Juries, Deliberative Polls, and Citizens' Assemblies. Most notably, there are variations in the size and the duration of minipublics. Moreover, the output of mini-publics varies from the aggregation of individual opinions to elaborate statements agreed by all participants (for a more detailed account of the key design features of mini-publics, see Farrell et al., 2019).

This article analyzes and evaluates the possible roles of minipublics as advisory, collaborative and scrutinizing institutions within representative democratic systems. The question raised in this article therefore pertains to the uptake of mini-publics' recommendations (Dryzek and Goodin, 2006) and the connection or coupling of mini-publics with representative democratic institutions (e.g. Hendriks, 2016; Setälä, 2017; Farrell et al., 2019). Because the focus is on interaction between mini-publics and elected representatives, I will not discuss those proposals (e.g. Bouricius, 2013) that entail the replacement of elected representative institutions with randomly selected bodies.

More precisely, this article addresses the question on whether and how mini-publics, when used in different roles, can complement current practices of representative democracy. The argument that mini-publics can complement representative institutions is made frequently in the academic literature (cf. e.g., Caluwaerts and Reuchamps, 2016; Kuyper and Wolkenstein, 2019) and in public discourse to justify their use in policymaking. For example, the Scottish Commission on Parliamentary Reform (2017), (64) characterizes the role of mini-publics as follows: "They complement and inform the decision making process but, crucially, do not replace the decision taking responsibility of members."

In order to evaluate whether mini-publics complement representative democracy, normative standards need to be established. In other words, the meaning of the term "complement" needs to be specified. Like other political institutions, deliberative mini-publics can be evaluated by their outcomes as well as by procedural standards. There are hopes that mini-publics could be a vehicle for a radical environmental and societal transformation (Hammond, 2020). For many, minipublics entail a promise of progressive policy changes (cf. Neblo, 2007) - at the same time others may be critical of them precisely for the same reason. Drawing on the theory of deliberative democracy, I argue that mini-publics should be evaluated on procedural grounds or, more precisely, whether they enhance inclusive processes of mutual justification among elected representatives responsible for collective decisions.

The evaluation of roles of mini-publics based on their capacity to enhance democratic deliberation among representatives is closely related to those studies assessing the democratic legitimacy of mini-publics (Caluwaerts and Reuchamps, 2016), and the legitimizing effects of mini-publics (Suiter et al., 2016). The aim is to develop a framework to evaluate roles of mini- publics based on their capacity to enhance democratic deliberation, and not to tackle the more fundamental normative question regarding the need for democratic deliberation in representative systems (cf. Kuyper and Wolkenstein, 2019).

In the following section, I will make the case for the evaluation of mini-publics on procedural grounds, that is, whether they enhance democratic deliberation among elected representatives who are responsible for political decisions. Improved quality of public deliberation at the representative arena can also have indirect effects such as enhancing learning and reflection among public at large, but these effects are only touched upon in the course of the article. When evaluating the normative and practical issues arising when mini-publics are used in advisory, collaborative and scrutinizing roles, I will use different examples to illustrate my argument. Since my study relies on secondary research, I will mainly refer to well-studied cases, or "prototypes," of using mini-publics in different roles. Although I refer to examples with particular mini-public designs, the issues discussed in this article are likely to arise also when other types of mini-public are used in similar roles.

\section{Mini-Publics and the Promise of Deliberative Democracy Democratic Deliberation as a Procedural Goal}

Some theorists of deliberative democracy have expressed concerns about the tendency of regarding deliberative minipublics as equal to deliberative democracy (Chambers, 2009, 324). Others have pointed out mini-publics' potential to enhance the quality of public deliberation, both among elected representatives and public at large (e.g. Niemeyer, 2014; Warren and Gastil, 2015). As democratic innovations, mini-publics are often expected to complement representative democracy, that is, to improve its quality somehow. Obviously, such expectations raise questions regarding the standards of evaluation. In the present article, the theory of deliberative democracy serves as a normative standard for the assessment of the quality of public decision-making.

According to the theory of deliberative democracy, the legitimacy of public decisions depends on the extent to which they are based on inclusive processes of mutual justification. In such processes, arguments are assessed equitably by their merits (cf. Habermas, 1996). In a process of democratic deliberation, the quality of arguments should be decisive, and factors such as speakers' identities or their social hierarchies should not play a role. Moreover, democratic deliberation is clearly different from some other political practices such as bargaining where participants' power resources are decisive or aggregative mechanisms such as voting.

Theorists of deliberative democracy have somewhat different emphases when it comes to the key features of deliberative democracy as a political system, as well as the value of deliberative democracy. For many, autonomy and popular selfgovernment are the key aspects of deliberative democracy (Rostbøll, 2008; Lafont, 2015). For some, deliberative democracy is an emancipatory project, promoting "leftist" - or 
just democratic - values such as equality (cf. Neblo, 2007). Others emphasize the epistemic benefits of deliberative processes - or, in other words, the capacity of deliberative democracy to bring about better informed and just political decisions (Estlund, 2008).

Apart from such instrumental understandings of deliberative democracy, many deliberative democrats are particularly concerned about the procedural aspects of democracy such as inclusion and equality. Notably, Young (2000) analyzes the mechanisms through which different individuals and groups are marginalized in the democratic decision-making process. Young points out various mechanisms of "external" and "internal" exclusion that are problematic from the normative perspective. Following Young's emphasis on the link between democracy and justice, the normative point of departure in this article is that democratic practices should remain sensitive to the existing patterns of political exclusion and develop responsiveness to the views and voices of especially those who are marginalized.

As a normative theory, the theory of deliberative democracy thus sets certain standards for evaluating democratic decisionmaking processes, most notably in terms of inclusion and the quality of public deliberation. There are good reasons to expect that good-quality, inclusive deliberation helps develop mutual understanding, or "meta-consensus" among deliberators (Dryzek and Niemeyer, 2006) and improve the quality of public decisions (Mercier and Landemore, 2012). However, it is hard or perhaps impossible to achieve intersubjective agreement regarding the quality of political decisions because the "fact of disagreement" will prevail in politics (also despite deliberation).

The standards of good-quality deliberative process are more complex and substantial than, for example, the criteria of democracy put forward in Dahl's (1989) procedural theory of democracy. As a consequence, the theory of deliberative democracy has been criticized for being an unrealistic model of politics (e.g. Richey, 2012; Achen and Bartels, 2016, 301, 324). As a normative theory, the theory of deliberative democracy cannot be falsified based on contrary empirical evidence (Mutz, 2008). Rather, it should be regarded as an aspirational theory that can be used in the evaluation of political systems and processes.

From the normative perspective of deliberative democracy, current representative democratic procedures seem to be deficient in many respects. While elections may be a good method of ensuring peaceful transitions of power (Przeworski, 1998), they are not particularly successful in terms of motivating the political key actors to engage in democratic deliberation. Electoral campaigns are geared towards winning votes, and parties and candidates speak and act in order to mobilize support and maximize votes (Chambers, 2009). Therefore, mass participatory process such as election campaigns and referendums tend to fall short of the standards of inclusive and good-quality deliberative process (Gastil, 2014; LeDuc, 2015). While representative institutions feature some forums particularly designed to foster democratic deliberation, most notably parliamentary committees (Chambers, 2009), partisan politics and government-opposition divide play an important role also in these forums.

\section{Mini-Publics Enhancing Democratic Deliberation}

The lack of deliberation in the key processes of representative politics may be outright frustrating for those who aspire for more inclusive, better justified and fact-based policy-making processes. Against this backdrop, the interest in democratic innovations such as deliberative mini-publics seems unsurprising. Minipublics have been particularly designed to enhance aspirations of deliberative democracy, most notably the inclusion of different societal viewpoints, interaction with expert information, and inclusive and balanced processes of mutual justification among citizens. Moreover, the design features of mini-publics such as random sampling and stratification, access to information and facilitated small group discussion can be expected to counteract those patterns of external and internal exclusion that can be detected in representative systems.

Although there is some evidence that factors such as education and gender may give rise to inequalities in mini-public deliberations (Gerber et al., 2016), mini-publics have usually performed rather well judged by the standards of deliberative democracy (Setälä and Smith, 2018). Studies show that participants of mini-publics learn a great deal about the issue at hand. In addition, they tend to become more understanding of the rationales of those with different viewpoints, even in deeply divided contexts (Andersen and Hansen, 2007; Luskin et al., 2014). Participants' opinions usually change in the deliberative process, and they tend to depolarize rather than become more extreme (Grönlund et al., 2015). Moreover, participants of minipublics are usually satisfied with their experience of participation, which may encourage them to participate in politics in the future.

While empirical studies seem to confirm the capacity of minipublics to enhance democratic deliberation among participants, the role of deliberative mini-publics in representative systems remains debatable. There are concerns that mini-publics remain weak institutions that create illusions of democracy without real empowerment (Fuji-Johnson, 2015). Moreover, there are concerns that mini-publics are used in an instrumental manner that support existing power structures by enhancing governmentality. These concerns are especially justified in cases where mini-publics are used by authoritarian governments to boost their problem-solving capacity (Woo and Kübler, 2020), but also democratically elected governments may use mini-publics instrumentally to promote certain policy goals or to strengthen their position in power (Setälä, 2011). At the same time, it must be kept in mind that, instead of some hidden agendas, policy-makers may be genuinely motivated in engaging citizens in resolving pressing policy issues. Nevertheless, doubts regarding motivations behind mini-publics are likely to arise when political trust is low, and especially among those opposing the government. And even when policy-makers are sincere in their interest in engaging and hearing citizens through mini-publics, there is a risk that this undermines the role of critical civil society.

According to some critics (e.g., Hammond, 2020), minipublics can turn out to be undemocratic because they may foreclose opportunities for critical deliberation in the wider public sphere. Lafont (2015) has further argued that minipublics can be detrimental to deliberative democracy if citizens 
blindly defer their independent, critical judgments to a minipublic. The worry is that, instead of using their own judgment, citizens might use mini-publics' recommendations as "cues" or "shortcuts" to be followed (cf. Lupia and McCubbins, 1998). So far, there seems to relatively little empirical evidence of such "blind deference" among the public. A more typical situation seems to be that a mini-public and its recommendations are hardly noticed by the public at large. In general, Lafont (2015) seems to have rather high expectations of prospects of citizens' critical reflection and deliberation given the multiplicity and the variety of political issues. From the perspective of democratic theory, some kind of division of deliberative labor is a necessary feature of representative systems (Warren, 2020).

The most important point to be learned from the critics like Lafont is that the success of mini-publics should be evaluated by their capacity to foster processes of public deliberation, i.e. mutual justification, learning and reflection in policy-making among those responsible for decisions and among the public at large. The focus should thus be on procedural aspects of mini-publics, that is, their capacity to improve inclusion and quality in the deliberative processes leading to collective decisions. In other words, the kinds of inclusive processes of mutual justification, learning and reflection observed in mini-publics should be "scaled up" (Niemeyer 2014). Measuring the impact of minipublics on the inclusiveness and the quality of deliberative processes leading to collective decisions is not straightforward, however, and it is definitely more complex than simply looking at more concrete outcomes such as policy changes brought about by mini-publics.

The procedural approach proposed in this paper does not seem to provide clear-cut standards for the evaluation of success of mini-publics. Since the processes of uptake are hard to observe, taking largely place "within" policy-makers, it is difficult to assess whether mini-publics' uptake is a result of careful consideration and reflection, or "cherry-picking," i.e. selective uptake of minipublics' recommendations. Admittedly, empirical studies on cherry-picking can give some indications also on the quality of processes of dealing with citizens' input (cf. Smith, 2009, 93; Font et al., 2018).

The prospects of "scaling up" are probably best demonstrated in studies on the Citizens' Initiative Review (CIR) (e.g. Gastil, 2014). In the CIR, a Citizens' Jury is convened to gather and evaluate facts and arguments related to a ballot initiative and summarize them in a statement delivered to all voters. The aim of the CIR is thus to reduce voters' cognitive costs by providing them with accessible and reliable summary of relevant information and arguments. There are studies showing that the CIR increases voters' knowledge on the issue at hand and understanding of different viewpoints regarding the ballot initiative (Knobloch et al., 2019). Some studies suggest further that the CIR process can counteract the effects of motivated reasoning among voters (Már and Gastil, 2019) and enhance learning and reflection even in polarized contexts (Setälä et al., 2020). Although the CIR process is designed to facilitate informed and reflected judgments among voters, successful mini-publics used in conjunction with representative institutions should give rise to similar processes of learning and reflection among elected representatives.

\section{Roles of Mini-Publics in Representative Politics}

From a very broad perspective, it may be argued that mini-publics can serve different functions in democratic systems (cf. Warren, 2017; Jäske and Setälä, 2019). Mini-publics are typically expected to contribute to processes of collective will-formation by allowing randomly selected citizens to contribute to deliberative processes preceding representative decision-making. And as shown by studies on CIR, mini-publics can also boost democratic deliberation among the public at large. Sometimes minipublics serve the function of political agenda-setting by bringing in new policy proposals for public deliberation and decision-making. For example, Dahl (1989), (340-341) already proposed a system including separate randomly selected minipublics (or mini-populi) for political agenda-setting and collective will-formation.

Deliberative mini-publics are rarely given powers to actually make political decisions, although there are proposals to delegate powers to mini-publics, or even to replace elections with random selection as a method of appointing decision-makers (Bouricius, 2013). There are many reasons for the reluctance to empower mini-publics. The most obvious reason is that the powers of elected representatives are constitutionally defined, and in many representative systems it is not possible to delegate these formal powers to other institutions without constitutional changes.

From a more principled perspective, while randomly selected mini-publics are designed to enhance descriptive representation, they lack the mechanisms of authorization and accountability that are characteristics of elected representative institutions such as parliaments (Parkinson, 2006, 33). Mini-publics could feature new forms of deliberative accountability where decisions made by a mini-public would be publicly justified and scrutinized by the general public. However, one key elements of electoral accountability, namely the possibility of the public to sanction decision-makers would still be missing in such accountability relations (cf. Gastil and Wright, 2018).

While the broad question about mini-publics' potential functions in a democratic system cannot be entirely addressed within the scope of the present article, the aim is to explore minipublics in a specific context, namely representative institutions such as parliaments. In what follows, I will explore three different roles of mini-publics in the context of representative democracy, namely as bodies that give advice for elected representatives, collaborate with elected representatives, and scrutinize decisions made by representatives. The purpose is to explore how minipublics, used in these different roles, can foster inclusive processes of learning, reflection and mutual justification among elected representatives who are in charge of making collectively binding decisions. The evaluation of mini-publics in these different roles is based on the theory of deliberative democracy, and procedural standards are an essential element in the evaluation of the different roles of mini-publics. 


\section{Mini-Publics as Advisory Bodies}

Mini-publics are typically advisory bodies that should help elected representatives to make decisions on a policy issue. This is the most wide-spread role given to mini-publics. Advisory mini-publics are expected to provide policy recommendations made, for example, by voting or by summarizing key arguments related to certain policy issue. As advisory bodies, mini-publics thus contribute to the functions of political agenda-setting and collective will-formation among elected representatives. The recommendations and summaries by mini-publics can help elected representatives to ponder various viewpoints related to a policy issue (Hendriks, 2016).

While advisory mini-publics are usually held on an ad hoc manner on a particular issue, there are also some examples of more regular uses of mini-publics e.g. in particular types of issues. A prototypical example of an advisory mini-public is the Danish model of Consensus Conferences (Andersen and Jæger, 1999). The Consensus Conference is a participatory method for technology assessment that is expected to complement information provided by experts on technically complex issues, as well as help explore and evaluate ethical aspects of the use of new technologies. The Consensus Conference is tasked to deliberate on the issue and to formulate a statement including the key factual findings and normative points of view relevant to the issue. The Consensus Conference consists of 14 citizens representing different sociodemographic and geographical segments of the society.

Between 1987 and 2002, altogether 22 Consensus Conferences were held in Denmark on various technically complex issues. The Consensus Conference model was developed by an independent governmental body, the Danish Board of Technology, which also chose the topics for citizen deliberation (Andersen and Jæerer, 1999). In this respect, the Danish model of Consensus Conferences seems to have been exceptional because advisory mini-publics are usually used on issues selected by policy-makers.

Danish Consensus Conferences dealt with various technically complex issues, such as genetic technology in agriculture, air pollution, human genome mapping, chemical substances, teleworking and electronic surveillance. The regular use of Consensus Conferences after the year 1987 until 2002 made it a rather well-known, (nearly) institutionalized practice which had a role, not just in parliamentary decision-making but also in public debate on technically complex issues more broadly. The statements by Consensus Conferences were delivered to Danish parliamentarians to help their decision-making on such complex issues. According to a study by Joss (1998), Consensus Conferences were appreciated by the MPs.

The example of Consensus Conferences shows that the role of mini-publics as advisory bodies is particularly important in technically complex issues which often do not spark inclusive public deliberation in the wider public sphere. More generally speaking, one might ask what is the purpose of advisory minipublics since they are doing more of less the same thing as parliamentary and select committees are supposed to do, namely to deliberate on policies in the light of evidence and across diversity of viewpoints. There are both normative and empirical approaches to this question (for a normative approach, see Kuyper and Wolkenstein, 2019). In empirical terms, the need for such "additional" processes of citizen deliberation is most likely to arise especially in complex technical and ethical issues where there are no straightforward partisan positions. Moreover, even when parliamentary deliberations are constrained by party discipline, citizen deliberation may be called for in polarizing issues that give rise to parliamentary deadlocks.

In the case of Danish Consensus Conferences, the statements were distributed to individual parliamentarians. There is evidence that the reports were read by the Danish parliamentarians; a survey shows that a clear majority of them claimed that they had done so, at least on some particular topics (Joss, 1998). Moreover, Consensus Conferences' reports were often referred to in parliamentary debates, and sometimes they led to parliamentary initiatives. However, in this model it was entirely up to individual MPs to decide whether to consider these recommendations and how to react to them. In the Danish case, individual MPs may have been particularly receptive to the arguments by Consensus Conferences because they dealt with issues that were rarely salient in representative politics or divisive according to partisan lines. Joss (1998) finds out that when it comes to issues dealt with by the Danish Consensus Conferences, there was often no party discipline in the parliament.

Overall, the method of uptake in Consensus Conferences is particularly vulnerable to cherry-picking, that is, selective uptake of recommendations. While cherry-picking seems to be a risk always when mini-publics are used as advisory bodies, there are also ways to circumvent this risk. The most promising model for uptake of mini-publics' arguments and recommendations is to submit them to parliamentary committees (Hendriks, 2016). Committee procedures potentially help parliamentary deliberation on recommendations by mini-publics - and thus avoid the most biased and selective interpretations of recommendations among elected representatives. Parliamentary committees are likely to be most receptive for mini-publics' recommendations since committees are, by design, expected to foster deliberation across different viewpoints, and they are characteristically more deliberative than plenary debates, for example.

There is still a risk that mini-publics' recommendations are not properly considered and watered down in the representative arena, especially if processes of parliamentary deliberation are flawed, for example, because of strict party discipline or logrolling. The impact of advisory mini-publics could be further strengthened by organizing dialogues between elected representatives and the members of a mini-public. This would allow members of the mini-public give feedback on the arguments made by elected representatives before the decisions are made. Dialogues between mini-publics and elected representatives could take place either in a parliamentary committee or at the plenary. Embedding such dialogue in committee deliberations may be recommendable for the reasons stated above, although in many cases this would mean that such dialogues are organized behind closed doors. 
Public dialogues between mini-publics and representatives would enhance deliberative accountability of representatives and serve the citizenry more broadly. However, the proximity of elections may affect representatives' public reactions to minipublics' proposals. In order to strengthen the impact of minipublics further, they could also follow up and give public feedback on decisions made by elected representatives. Such arrangements would go beyond the purely advisory role of mini-publics by allowing mini-publics to intervene or to scrutinize representative decision-making.

\section{Mini-Publics as Collaborative Institutions}

Because purely advisory uses of mini-publics are so vulnerable to cherry-picking, there seems to be a need for a tighter coupling between mini-publics and elected representatives (Hendriks, 2016). One response to mini-publics' lack of impact is to involve decision-makers in the deliberative process more directly. As already pointed out, there are various possible models of organizing interactions between mini-publics and elected representatives, including hearings of representatives in mini-publics, and mini-publics' members hearings in the representative arena.

However, those responsible for decisions, i.e. elected representatives, could also directly engage in a deliberative process with a cross-section of the society. In this model, randomly selected citizens would participate in parliamentary will-formation more directly. While these types of practices have not been very common so far, there are a few important examples. Most notably, the Irish Constitutional Convention, oganized in 2012-2014, included 66 randomly selected citizens and 33 members of the Irish Parliament. The Irish Constitutional Convention deliberated on several constitutional issues ranging from electoral laws to same-sex marriage. It brought about certain important constitutional changes, most notably the legalization of same-sex marriage (Suiter et al., 2016).

There are also other models of mixing elected representatives and citizen deliberation. In the model of 'directly deliberative democracy', developed and experimented by Neblo et al. (2018), members of the US Congress engage in online deliberations with a randomly selected cross-section of their constituents. The model of "hybrid democracy" developed by Sørensen and Torfing (2019), municipal councilors deliberate on a particular policy issue together with citizens representing certain affected groups. Because "hybrid democracy" aims at the inclusion of affected groups rather than randomly selected representatives of the public at large, the model seems to be closer to stakeholder participation than mini-publics.

The inclusion of elected representatives in mini-publics could enhance inclusive processes of mutual justification in policymaking at least in three different ways. First, by engaging in minipublics' deliberations, elected representatives are likely to be exposed to a larger variety of societal viewpoints than in deliberations among representatives only. They may encounter new viewpoints and claims, including those by marginalized groups. This should also encourage representatives to reflect their own views, to correct their possible biases, and help find constructive solutions to the issues at hand.
Second, the procedural features of mini-publics such as interaction with experts, discussion rules, and moderated small group discussions are likely to help elected representatives become more open-minded to different societal viewpoints and overcome their pre-established partisan positions. In fact, the procedures applied in deliberative mini-publics are likely to be more conducive to good-quality deliberation than those applied, e.g. in parliamentary committees. Third, after engaging in such a deliberative process, representatives are likely to be more supportive of the claims and arguments developed in the deliberative process and advocate them in actual decisionmaking. This is likely to enhance the inclusion of different viewpoints and the quality of deliberation in the actual political decision-making.

While mixed deliberative bodies can be expected to improve inclusion and deliberative quality in collective will-formation among elected representatives, there are several questions that need to be taken into account when including elected representatives in deliberative mini-publics. The involvement of partisan politicians may distort the deliberative process. It may increase the tendencies towards partisan reasoning if randomly selected citizens follow the opinions of representatives of their 'own' party. And perhaps even more importantly, representatives' involvement may create inequalities and hierarchies within the deliberative forum, which may distort the deliberative process.

Professional politicians may also dominate the discussions because of their (arguably) better knowledge of the issue at stake or of politics more generally. Or professional politicians may undermine the deliberative process by using partisan rhetoric or other non-deliberative styles of persuasion that are typical in representative politics. However, certain design features of minipublics such as interaction with experts and good-quality facilitation may counteract inequalities and non-deliberative communication styles as well as alleviate such problems. In addition, attention should be paid to the ratio between the number of representatives and citizens in the deliberative forum.

Studies on the deliberative process in the Irish Constitutional Convention seem to dispel some of the concerns regarding mixed forums. There is some evidence that politicians did not dominate the deliberative process in the Constitutional Convention (Suiter et al., 2016). However, the experiences of mixing professional politicians with ordinary citizens in the UK context were less promising (Flinders et al., 2016, 36-40). There have also been concerns pertaining to the risk of selection bias among politicians participating in the deliberative forum. Yet, such biases seem not to have played an important role in case of the Irish Constitutional Convention (Farrell et al., 2019).

Since the evidence of such processes is still scarce, it is hard to draw conclusions on the contextual and design factors affecting the quality of mixed deliberation. Another problem with mixed deliberation is probably that, although elected representatives' views may actually be influenced by the arguments put forward in the mini-public, they may still remain selective in their interpretations of mini-publics arguments and recommendations. In other words, there is a risk of cherry-picking also in mixed mini-publics. For example, in the Irish Constitutional 
Convention, elected representatives seem to have been reluctant to promote policy recommendations regarding, for example, the electoral system, that are potentially against their own vested interests (cf. Farrell et al., 2019).

In the case of advisory mini-publics, it is be possible to develop opportunities for a mini-public to give feedback on the decisions made by elected representatives. However, it is hard to see how this could work in mixed mini-publics. In this respect, the lack of critical distance between mixed mini-publics and elected representatives seems to be a problem. This could also be regarded as a reason to keep mini-publics separate from elected representative institutions. While such a separation may lead to lack of impact in case of advisory mini-publics, one solution would be to use mini-publics more systematically to scrutinize the decisions already made by elected representatives.

\section{Mini-Publics Scrutinizing Representative Institutions}

There have been calls for critical mini-publics that would enhance critical reflection and deliberation among policy-makers and the public at large (Böker and Elstub, 2015). For this purpose, minipublics should perhaps remain separate and independent from elected representatives. In addition, they should be allowed to scrutinize and publicly challenge the decisions made and justifications given by elected representatives. While there are several proposals for the use of mini-publics in this kind of a scrutinizing role, the actual examples of such usages are still scarce.

However, as the model of Citizens' Initiative Review illustrates, deliberative mini-publics are apt to scrutinizing of policy proposals. While the CIR model was developed to assess the merits of ballot initiatives, it is possible to imagine a system where a mini-public would scrutinize governmental policy proposals or, for example, so-called agenda initiatives, i.e. citizens' initiatives submitted to parliament. There are also models in which mini-publics are expected to function as an ex post check on decisions that have been made by elected representatives. As pointed out already, models allowing advisory mini-publics to follow up representative decisionmaking or requirement of representatives' public response to a mini-public's recommendation would entail some elements of scrutiny.

Notably, there is at least one existing practice involving a system of mini-publics with both advisory and scrutinizing powers, namely the so-called Ostbelgien model. In this model, mini-publics have a role in both preparing policy proposals and following up the parliamentary system's response to these proposals (Reuchamps, 2019). The model includes a Citizen Council which is in charge of setting the agenda and monitoring the progress of its proposals. In addition, separate Citizen Assemblies are tasked to prepare the details of the proposals put forward by the Citizen Council. In this respect, the Ostbelgien model allows mini-publics to contribute to various democratic functions, namely agenda-setting, collective willformation and (deliberative) accountability.
The opportunity of mini-publics to exercise ex post scrutiny of elected representatives enhances deliberative accountability of elected representatives by "forcing" them to justify their views to a deliberative body representing a diverse group of citizens. Such mechanisms of deliberative accountability should encourage elected or non-elected - representatives to consider a wider range of viewpoints already in the deliberative process leading to decisions. In the Ostbelgien model, the scrutinizing role of the Citizen Council is limited to the issues that it has raised onto the political agenda. In this respect, the Citizen Council appears to be in a good position to hold the elected representative deliberatively accountable on these particular issues.

There are also other possible models of using mini-publics to scrutinize representative decision-making. Mini-publics could be used to review decision-making in certain types of decisions or in particular circumstances. For example, the Covid-19 pandemic has led many governments to resort exceptional legislation and procedures for cases of emergency, which has further emphasized the role of the executive government in policy-making. Minipublics could be used retrospectively to scrutinize the policy measures taken during the pandemic in order to develop democratic systems' preparedness for future cases of emergency. Or, mini-publics could be routinely used to evaluate the work of the government, for example, in the end of the parliamentary term.

Another way of sharpening the role of a randomly selected chamber would be to specify its scrutinizing task. MacKenzie (2020) suggests that, as a remedy to the problem of democratic myopia, randomly selected citizens could be tasked to scrutinize laws based on the mandatory posteriority impact statements that summarize the anticipated long-term consequences of legislation. In this model, a clearly defined task would give a focus to the work of the randomly selected citizens. Moreover, a systematic use of mini-publics in this kind of a scrutinizing role would encourage elected representatives to consider the long-term consequences of different policy options more carefully.

In the Ostbelgien model, mini-publics have both advisory and scrutinizing roles, which can seems to be a good model in terms of enhancing the impact of citizen deliberation without compromising their independence. Moreover, the Ostbelgien model makes mini-publics a permanent and institutionalized part of the legislative system. In this respect, it shares some features of randomly selected second chambers. Because of the careful design and the institutionalization, the Ostbelgien model is probably the promising model of how mini-publics can be given a scrutinizing role in the legislative system without formal empowerment.

\section{From Mini-Publics to Randomly Selected Second Chambers?}

There are proposals to go even further and to give randomly selected citizens some formal powers in collective decisionmaking. Various authors (e.g. Leib, 2004; MacKenzie, 2016; Vandamme and Verret-Hamelin, 2017; Gastil and Wright, 2018) have discussed the idea of a randomly selected second chamber. Of course, such formal empowerment of randomly 
selected bodies would not be possible in most representative democracies without constitutional changes.

There are different views about the extent and types of formal powers vested to randomly selected second chambers. Some of these proposals (e.g. Leib, 2004; Gastil and Wright, 2018) suggest a bicameral system were the powers of the randomly selected chamber would be more or less symmetrical with the elected legislative chamber. Others (e.g. MacKenzie, 2016) have suggested a less radical model where the randomly selected chamber would have powers to delay legislation. In this respect, randomly selected chambers would not be actual veto players in the political system, but rather something like second chambers in systems characterized by asymmetric bicameralism, such as the UK (cf. Parkinson, 2007, 380).

The justification for a randomly selected second chamber is that it would allow an inclusive deliberative process which is free from hindrances of parliamentary deliberation such as party discipline and constituency constraints. Like other institutions that have been designed to enhance inclusive public scrutiny, such as facultative referendums (El-Wakil, 2016), randomly selected second chambers with veto powers could have anticipatory effects on elected representatives. In order to avoid delays in legislation, elected representatives would need to anticipate and take into account various counterarguments to their policy views, which would enhance the inclusion of different viewpoints and the quality of deliberation among elected representatives. In case of actual challenge by the randomly selected second chamber, disagreements with elected representatives and randomly selected chambers would be articulated in the public. This could also be valuable from the perspective of deliberative democracy since it might help public at large to form their own views on the topic based on such exchanges of arguments.

MacKenzie (2016), MacKenzie (2020) argues for a randomly selected, general-purpose second chamber that has powers to scrutinize and delay any legislation passed by elected representatives. MacKenzie argues that a randomly selected second chamber would have instrumental benefits since it would help considerations of long-term policy consequences. MacKenzie would not limit the powers of such second chamber to any specific issue area, but would prefer a "general-purpose" second chamber. Consequently, randomly selected citizens would need to follow and develop competence on a range of policy areas in order to exercise the scrutinizing function in a credible manner.

To address the potential problems of competence among randomly selected citizens, Gastil and Wright (2018) suggest a long tenure for randomly selected chambers as well as similar support systems including training and professional aides as elected representatives have. However, it is still questionable whether and how randomly selected citizens could develop sufficient expertise on all relevant policy areas. Studies show that there are divisions of labor among elected representatives and parliamentarians specialize in and develop their expertise on certain issue areas e.g. by serving in particular committees (cf. Oñate and Ortega, 2019).
Of course, the institutionalization of a randomly selected second chamber goes beyond of any of the currently existing practices of mini-publics. In addition, a number of questions arise regarding the practical implementation of such institutions There are concerns that the authorization of a randomly selected chamber would put it under similar pressures as elected representatives, which would hinder constructive deliberation within the forum. Moreover, the lack of accountability of randomly selected chambers could give rise to situations where their legitimacy is challenged. As Gastil and Wright (2018) point out, these kinds of concerns could at least partly be addressed by a careful institutional design.

From the point of view of the feasibility of randomly selected second chambers, the biggest problem may be that elected representatives are likely to remain reluctant to adopt them or, even when adopted, to pay enough attention to the careful design that such institutions would require. The main reason is that such institutions could potentially undermine the role of elected representatives - or even appear as antagonistic. While the institutionalization of scrutinizing mini-publics or randomly selected second chambers may look like an excellent idea from the perspective of deliberative democracy, it may be a rather long shot in the context of representative democracies. Obviously, this is rather a practical challenge for the adoption of such institutions rather than a principled reason to object them.

\section{DISCUSSION}

The evaluation of mini-publics should be based on a procedural criterion of whether mini-publics help enhance the inclusive and good-quality deliberation among elected representatives. While inclusive deliberative processes are likely to improve the quality of public decisions (cf. Mercier and Landemore, 2012), the evaluation of the quality of decisions may only be possible "with the benefit of a hindsight."Admittedly, mini-publics are not the only way of enhancing inclusiveness and quality of deliberation among elected representatives. Parliamentary procedures could be developed to improve the quality of deliberation, and interaction and communication between parliaments and citizens could be encouraged by variety of means (cf. Leston-Bandeira, 2012).

The purpose of this article has been to analyze the potential roles of deliberative mini-publics in representative systems. It has been argued that mini-publics can be used to advise elected representatives in decision-making, to collaborate with them in making better decisions, or to scrutinize decisions they have already made. In addition, normative perspective of deliberative democracy has been applied to analyze the expected benefits and weaknesses of using mini-publics in these different roles. Table 1 summarizes the expected benefits, main weaknesses of using mini-publics in different roles, as well as possible remedies to these problems.

The risks of cherry-picking are especially high in advisory mini-publics. These risk can be potentially alleviated if parliamentary committees deliberate on mini-publics' recommendations. And even more so, cherry-picking 
TABLE 1 | The summary of benefits and weaknesses involved in different roles of mini-publics.

\begin{tabular}{|c|c|c|c|}
\hline Mini-public's role & Expected benefit & Main weakness & Remedy \\
\hline Advisory & reflection and enhanced deliberation & cherry-picking & enhancing representative deliberation on recommendations \\
\hline Collaborative & more inclusive deliberation & dominance by representatives & ensuring the quality of deliberation e.g. by facilitators \\
\hline Scrutinizing & deliberative accountability & antagonizing representatives & clarifying the terms of scrutiny \\
\hline
\end{tabular}

tendencies can be counteracted by involving representatives directly in the deliberative process. While models where elected representatives deliberate together with randomly selected citizens seem to be a viable way of enhancing inclusiveness and quality of deliberation, they entail a risk of representative dominance and co-optation. These problems can, in turn, be remedied by good facilitation and careful design of the deliberative process. Scrutinizing mini-publics can enhance deliberative accountability of elected representatives and the quality of representative deliberation in anticipation of minipublics.

The overall conclusion is the impact of mini-publics can be bolstered by enhancing deliberative interactions between mini-publics and elected representatives. This can be done, for example, by combining advisory with scrutinizing roles of mini-publics. At the same time, the actual impact of minipublics may remain highly contingent on the contextual factors such as the type of issue at hand and the partypolitical constellation. Advisory and collaborative minipublics can have more impact in situations where there is no strict government-opposition divide. In such situations, there is more room for parliamentary deliberation and, consequently, openness for mini-publics' arguments and recommendations. In contrast, in political contexts allowing little room for deliberation within the representative arena, due to executive dominance or strict government-opposition divide, scrutinizing mini-publics with actual veto powers may be the only way to ensure the deliberative impact of mini-publics.

\section{REFERENCES}

Achen, C. H., and Bartels, L. M. (2016). Democracy for realists. Princeton, NJ: Princeton University Press.

Andersen, I., and Jæger, B. (1999). Danish participatory models. Scenario workshops and consensus conferences: towards more democratic decision-making. Sci. Publ. Pol. 26 (5), 331-340. doi:10.3152/ 147154399781782301

Andersen, V. N., and Hansen, K. M. (2007). How deliberation makes better citizens: the Danish Deliberative Poll on the euro. Eur. J. Polit. Res. 46, 531-556. doi:10.1111/j.1475-6765.2007.00699.x

Böker, M., and Elstub, S. (2015). The possibility of critical mini-publics: realpolitick and normative cycles in democratic theory. Representation 51 (1), 125-144. doi:10.1080/00344893.2015.1026205

Bouricius, T. G. (2013). Democracy through multi-body sortition: athenian lessons for the modern day. J. Public Deliberation. 9 (1), 11. doi:10.16997/jdd.156

Brown, M. (2006). Survey article: citizen panels and the concept of representation. J. Polit. Philos. 14 (2), 203-225. doi:10.1111/j.1467-9760.2006.00245.x

Caluwaerts, D., and Reuchamps, M. (2016). Generating democratic legitimacy through deliberative innovations: the role of embeddedness and disruptiveness. Representation 52 (1), 13-27. doi:10.1080/00344893.2016.1244111
Finally, there is a need to develop methodologies of examining mini-publics' uptake among elected representatives. In order to examine the "hidden" aspects of uptake (cf. Hendriks and LeesMarshment, 2019), it is necessary to gauge whether exposure to mini-public's recommendations enhances learning and reflection on different viewpoints among elected representatives. For this purpose, it would be important to conduct carefully designed interviews and surveys among elected representatives before and after mini-publics, as well as to observe and analyze representatives' deliberation on mini-publics' recommendations.

\section{DATA AVAILABILITY STATEMENT}

The original contributions presented in the study are included in the article/Supplementary Material, further inquiries can be directed to the corresponding author.

\section{AUTHOR CONTRIBUTIONS}

The author confirms being the sole contributor of this work and has approved it for publication.

\section{FUNDING}

This work was supported by the Strategic Research Council at the Academy of Finland (grant number 312671).

Chambers, S. (2009). Rhetoric and the public sphere: has deliberative democracy abandoned mass democracy? Polit. Theor. 37 (3), 323-350. doi:10.1177/ 0090591709332336

Commission on Parliamentary Reform (2017). Report on the scottish parliament. Available at:https://spark.adobe.com/page/QKq29aXYqB6mK/ (Accessed December 8, 2020).

Dahl, R. A. (1989). Democracy and its critics. New Haven, CT and London: Yale University Press.

Dryzek, J., and Niemeyer, S. (2006). Reconciling pluralism and consensus as political ideals. Am. J. Polit. Sci. 50 (3), 634-649. doi:10.1111/j.1540-5907. 2006.00206.x

Dryzek, J. S., and Goodin, R. E. (2006). Deliberative impacts: the macro-political uptake of mini-publics. Polit. Soc. 34, 219-244. doi:10.1177/0032329206288152

El-Wakil, A. (2016). The deliberative potential of facultative referendums: Procedure and substance in direct democracy. Democratic Theory. 4, 59-78. doi:10.3167/dt.2017.040104

Estlund, D. M. (2008). Democratic authority. A philosophical framework. Princeton, NJ: Princeton University Press.

Farrell, D. M., Curato, N., Dryzek, J. S., Geißel, B., Grönlund, K., Marien, S., Niemeyer, S., et al. (2019). Deliberative mini-publics: core design features. Canberra, Australia: Centre for Deliberative Democracy \& Global Governance, University Canberra. 
Farrell, D. M., Suiter, J., Harris, C., and Cunningham, K. (2019). The effects of mixed membership in a deliberative forum: the Irish constitutional convention of 2012-2014. Polit. Stud. 68, 54-73. doi:10.1177/0032321719830936

Fishkin, J. S. (2009). When the people speak: deliberative democracy and public consultation. Oxford, UK: Oxford University Press.

Flinders, M., Ghose, K., Jennings, W., Molloy, E., Prosser, B., Renwick, A., et al. (2016). Democracy matters: lessons from the 2015 citizens' Assemblies on English devolution. Sheffield, UK: Democracy Matters.

Font, J., Smith, G., Galais, C., and Alarcon, P. (2018). Cherry-picking participation: explaining the fate of proposals from participatory processes. Eur. J. Polit. Res. 57. 615-636. doi:10.1111/1475-6765.12248

Fuji Johnson, G. (2015). Democratic illusion. Deliberative democracy in Canadian public policy. Toronto, Canada: University of Toronto Press.

Gastil, J. (2014). Beyond endorsements and partisan cues: giving voters viable alternatives to unreliable cognitive shortcuts. Good Soc. 23 (2), 145-159. doi:10. 1353/gso.2014.0014

Gastil, J., and Wright, E. O. (2018). Legislature by lot: envisioning sortition within a bicameral system. Polit. Soc. 46 (3), 303-330. doi:10.1177/0032329218789886

Gerber, M., Bächtiger, A., Shikano, S., Reber, S., and Rohr, S. (2016). Deliberative abilities and deliberative influence in a transnational deliberative poll (EuroPolis). Br. J. Polit. Sci. 48, 1098-1118. doi:10.1017/S0007123416000144

Grönlund, K., Herne, K., and Setälä, M. (2015). Does enclave deliberation polarize opinions? Polit. Behav 37 (4), 995-1020. doi:10.1007/s11109-015-9304-x

Habermas, J. (1996). Between facts and norms. Cambridge, MA: The MIT Press.

Hammond, M. (2020). Democratic innovations after the postdemocratic turn: between activation and empowerment. Crit. Pol. Stud. doi:10.1080/19460171. 2020.1733629

Hendriks, C. (2016). Coupling citizens and elites in deliberative systems: the role of institutional design. Eur. J. Polit. Res. 55 (1), 43-60. doi:10.1111/1475-6765.12123

Hendriks, C. M., and Lees-Marshment, J. (2019). Political leaders and public engagement: the hidden world of informal elite-citizen interaction. Polit. Stud. 67 (3), 597-617. doi:10.1177/0032321718791370

Jäske, M., and Setälä, M. (2019). A functionalist approach to democratic innovations. Representation 56, 1-17. doi:10.1080/00344893.2019.1691639

Joss, S. (1998). Danish consensus conferences as a model of participatory technology assessment: an impact study of consensus conference on Danish Parliament and Danish public debate. Sci. Publ. Pol. 25 (1), 2-22.

Knobloch, K., Barthel, M., and Gastil, J. (2019). Emanating effects: the impact of the Oregon citizens' initiative review on voters' political efficacy. Polit. Stud. 68, 426-445. doi:10.1177/0032321719852254

Kuyper, J. W., and Wolkenstein, F. (2019). Complementing and correcting representative institutions: when and how to use mini-publics. Eur. J. Polit. Res. 58, 656-675. doi:10.1111/1475-6765.12306

Lafont, C. (2015). Deliberation, participation and democratic legitimacy: should deliberative minipublics shape public policy? J. Polit. Philos. 23 (1), 40-63. doi:10.1111/jopp.12031

LeDuc, L. (2015). Referendums and deliberative democracy. Elect. Stud. 38, 139-148. doi:10.1016/j.electstud.2015.02.007

Leib, E. J. (2004). Deliberative democracy in America: a proposal for a popular branch of government. Park, PA: University of Pennsylvania State University Press.

Leston-Bandeira, C. (2012). Studying the relationship between parliament and citizens. J. Legis. Stud 18 (3-4), 265-274. doi:10.1080/13572334.2012. 706044

Lupia, A., and McCubbins, M. D. (1998). The democratic dilemma: can citizens learn what they need to know? Cambridge, UK: Cambridge University Press.

Luskin, R. C., O'Flynn, I., Fishkin, J. S., and Russell, D. (2014). Deliberating across deep divides. Polit. Stud. 62, 116-135. doi:10.1111/j.1467-9248.2012.01005.x

Már, K., and Gastil, J. (2019). Tracing the boundaries of motivated reasoning: how deliberative minipublics can improve voter knowledge. Polit. Psychol. 41, 107-127. doi:10.1111/pops.12591

MacKenzie, M. (2016). "A general-purpose, randomly selected chamber", in Political institutions for future generations, Editors A. Gosseries and I. González-Ricoy (Oxford, UK: Oxford University Press), 282-299.

MacKenzie, M. (2021). There is No such thing as a short-term issue. Futures 125, 102652. doi:10.1016/j.futures.2020.102652

Mercier, H., and Landemore, H. (2012). Reasoning is for arguing: understanding the successes and failures of deliberation. Polit. Psychol. 33 (2), 243-258. doi:10. $1111 / \mathrm{j} .1467-9221.2012 .00873 . \mathrm{x}$
Mutz, D. C. (2008). Is deliberative democracy a falsifiable theory? Annu. Rev. Polit. Sci. 11, 521-538. doi:10.1146/annurev.polisci.11.081306.070308

Neblo, M., Esterling, K., and Lazer, D. (2018). Politics with the people. Building a directly representative democracy. Cambridge, UK: Cambridge University Press.

Neblo, M. (2007). Family disputes: diversity in defining and measuring deliberation. Swiss Polit. Sci. Rev. 13 (4), 527-557. doi:10.1002/j.1662-6370.2007.tb00088.x

Niemeyer, S . (2014). "Scaling up deliberation to mass publics: harnessing mini-publics in a deliberative systems", in Deliberative mini-publics, Editors K. Grönlund, A. Bächtiger, and M. Setälä (Colchester, UK: ECPR Press), 177-202.

Oñate, P., and Ortega, C. (2019). Committee Parliamentary Specialization Index. Explaining MPs' specialisation in the Spanish Congreso de los Diputados. J. Legis. Stud. 25 (3), 394-408. doi:10.1080/13572334.2019.1662610

Parkinson, J. (2006). Deliberating in the real world: problems of legitimacy in deliberative democracy. Oxford, UK: Oxford University Press.

Parkinson, J. (2007). House of lords. A deliberative democracy defence. Polit. Q 78 (3), 374-381. doi:10.1111/j.1467-923X.2007.00866.x

Przeworski, Adam. (1998). "Minimalist conception of democracy: a defence." in Democracy's value. Editors I. Shapiro and C. Hacker-Cordón. (Cambridge, UK: Cambridge University Press), 23-56.

Reuchamps, M. (2019). Towards permanent deliberative democracy in Belgium: from the G1000 to the Ostbelgien Model. Canberra, Australia: School of Politics and International Relations Seminar, ANU

Richey, M. (2012). Motivated reasoning in political information processing: the death knell of deliberative democracy. Philos. Soc. Sci. 42 (4), 511-542. doi:10. 2139/ssrn.2056190

Rostbøll, C. (2008). Deliberative freedom: deliberative democracy as critical theory. Albany, NY: State University of New York Press.

Sørensen, E., and Torfing, J. (2019). Towards robust hybrid democracy in Scandinavian municipalities? Scand. Polit. Stud. 42 (1), 25-49. doi:10.1111/1467-9477.12134

Setälä, M. (2011). The role of deliberative mini-publics in democratic systems. Lessons from the experience of referendums. Representation 47 (2), 201-213.

Setälä, M. (2017). Connecting deliberative mini-publics to representative decisionmaking. Eur. J. Political Res. 56, 846-863. doi:10.1111/1475-6765.12207

Setälä, M., Christensen, H. S., Leino, M., Strandberg, K., Bäck, M., and Jäske, M. (2020). Deliberative mini-publics facilitating voter knowledge and judgement: experience from a Finnish local referendum. doi:10.1080/00344893.2020.1826565

Setälä, M., and Smith, G. (2018). "Deliberative mini-publics and deliberative democracy." in The Oxford handbook of deliberative democracy, Editors A. Bächtiger, J. Dryzek, J. Mansbridge, and M. Warren. (Oxford, UK: Oxford University Press), 300-314.

Smith, G. (2009). Democratic Innovations. Designing Institutions for Citizen Participation. Cambridge: Cambridge University Press.

Suiter, J., Farrell, D., and Harris, C. (2016). "The Irish constitutional convention: a case of 'high legitimacy'?", in Constitutional deliberative democracy in Europe, Editors M. Reuchamps and J. Suiter (Colchester: ECPR Press), 33-52.

Vandamme, P.-E., and Verret-Hamelin, A (2017). A randomly selected chamber: promises and challenges. J. Public Deliberation 13 (1), 5. doi:10.16997/jdd.271

Warren, M. E. (2017). A problem-based approach to democratic theory. Am. Polit. Sci. Rev. 111 (1), 39-53. doi:10.1017/S0003055416000605

Warren, M. E., and Gastil, J. (2015). Can deliberative minipublics address the cognitive challenges of democratic citizenship. J. Polit. 77 (2), 582-574. doi:10.1086/680078

Warren, M. E. (2020). Participatory deliberative democracy in complex mass societies. Journal of Deliberative Democracy. 16, 81-88. doi:10.16997/jdd.395

Woo, S. Y., and Kübler, D. (2020). Taking stock of democratic innovations and their emergence in (unlikely) authoritarian contexts. Polit. Vierteljahresschr. (PVS) 61, 335-355. doi:10.1007/s11615-020-00236-4

Young, I. M. (2000). Inclusion and democracy. Oxford, UK: Oxford University Press.

Conflict of Interest: The author declares that the research was conducted in the absence of any commercial or financial relationships that could be construed as a potential conflict of interest.

Copyright $\odot 2021$ Setälä. This is an open-access article distributed under the terms of the Creative Commons Attribution License (CC BY). The use, distribution or reproduction in other forums is permitted, provided the original author(s) and the copyright owner(s) are credited and that the original publication in this journal is cited, in accordance with accepted academic practice. No use, distribution or reproduction is permitted which does not comply with these terms. 